\title{
A Multi Biometric IRIS Recognition System based on a Profound Learning Method
}

\author{
S. Janardhanarao, V.Jyothi
}

\begin{abstract}
Biometrics is the estimation of natural qualities which are one of a kind to a person for recognizing and confirming the person. The estimations incorporate fingerprints, retinal outputs, iris checks, voice designs, facial qualities, palm prints, and so forth.., Biometric frameworks have been especially effective in distinguishing an obscure individual via looking through a database of attributes and by confirming the case of a person by contrasting his/her trademark with that put away in a database. To expand the heartiness of the framework and to make it more secure, different attributes of a similar individual are utilized. This is alluded to as multimodal biometrics. In this paper we talked about a portion of the multimodal biometric frameworks. Here a bi-modular biometric acknowledgment framework in light of iris, palm-print. Wavelet and curve let change and Gabor-edge channel are utilized to extricate includes in various weighing machine moreover introductions starting iris as well as palm print, finer points taking out in addition to arrangement is utilized in favour of coordinating. diverse combination calculations together with achieve based, positionbased plus choice depend on techniques are utilized to-join the consequences of two constituents. We additionally recommend another rank-based combination calculation Bio Maximum Inverse Rank (BMIR) which is vigorous as for varieties in scores and furthermore awful positioning from a module. IITD iris databases and CASIA datasets for palm print and unique mark are utilized in this investigation. The examinations demonstrate the adequacy of our combination strategy, profound learning, neural systems and our Bi-modular biometric acknowledgment framework in contrast with existing multi-modular acknowledgment frameworks.
\end{abstract}

Keywords: Iris appreciation, Multi modal biometric systems, Deep learning, Convolution Neural Network, Decision Fusion

\section{INTRODUCTION}

Recognizing and confirming a man is indispensable in most secure applications. Conventional techniques like ID card, passwords can be effortlessly copied, lost or stolen[1]. Additionally these strategies are helpful for confirmation just and not for distinguishing proof. To beat these issues, biometric highlights like fingerprints, iris check, confront, walk, palm-print started to be utilized. These highlights prompted the utilization of biometric frameworks. In these frameworks any one biometric was utilized. Yet, these single biometric frameworks likewise confronted issues like commotion in the detected information, non-all inclusiveness and helplessness to circumvention.

Revised Manuscript Received on October 21, 2019.

S.Janardhanarao, Associate professor, Vardhaman College of engineering

V.Jyothi, Assistant professor, Vardhaman College of engineering
Thus another classification is utilizing at least two biometric highlights; called multimodal biometrics has been created in the ongoing years.

\section{IRIS}

In people and most well evolved creatures and feathered creatures, the iris (plural: irides or irises) is a thin, round formation in the eye, in charge of domineering the width in addition to amount of the understudy also along these lines the measure of brightness achieving the retina. Eye shading is characterized to facilitate of the iris. In visual provisos, the student is the eye's opening, although the iris is the stomach.

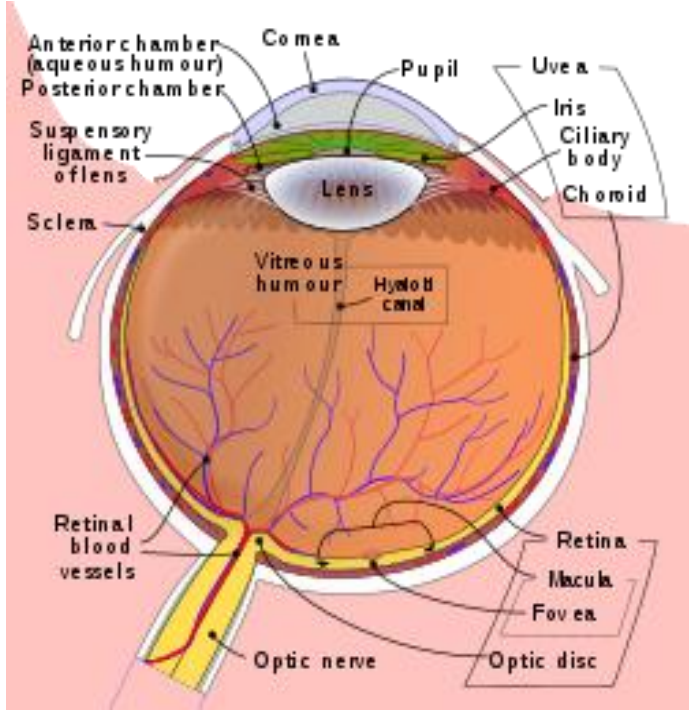

Fig. 1 Human eye. (Iris labelled at upper right)

The iris comprises of 2 layers: The front pigmented fibro vascular layer identified as a storm and, underneath the stroma, pigmented epithelial units. The stroma interfaces with a sphincter muscle (sphincter pupillae), which gets the understudy in a round movement, along with an arrangement of dilator-muscles (dilator pupillae) which pull the iris radically to develop the student, dislocate it in folds[2]. The reverse exterior is secured by a vigorously pigmented epithelial layer to facilitate is 2 cells solid (the iris shade epithelium), yet the frontage outside has no epithelium. This front shell ventures as the dilator brute force. The towering shade satisfied squares illumination from going from first to last the iris to the retina, limiting it to the understudy. The external boundary of the iris, celebrated as the root, is fixed to the sclera moreover the front ciliary body. The iris furthermore ciliary body mutually are known as the front uvea. presently before the

\section{Published By:}

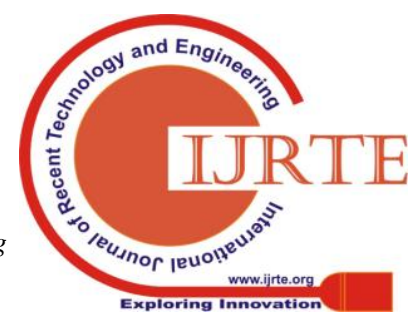


foundation of the iris is the locale alluded en route for the trabecular meshwork, during which the fluid funniness always depletes out of the eye, with the outcome that sicknesses of the iris regularly effect sly affect intraocular weight and by implication on vision. The iris alongside the front ciliary body gives an auxiliary pathway to watery silliness to deplete starting the eye.

\section{The iris is separated into 2 major regions}

1. The pupillary sector is the internal locale whose frame shapes the limit of the understudy.

2. The ciliary region is whatever is left of the iris with the purpose of reaches out towards its birthplace at the ciliary remains.

The collarette is the thickest district of the iris, isolating the pupillary bit beginning the ciliary segment. The collarette is a fundamental of the covering of the embryonic pupil.[1] It is regularly characterized as the locale anywhere the sphincter influence also dilator muscle cover. Spiral edges stretch out as of the fringe near the pupillary sector, to supply the iris among veins. The foundation of the iris is the most slender and generally peripheral[3].

The muscle cells of the iris be horizontal muscle in warm blooded animals in addition to creatures of land and water, yet be striated muscle in reptiles (counting feathered creatures). Many catch fish contain not one or the other, and, therefore, their irides can't enlarge and contract, with the goal that the understudy dependably stays of a settled size.

\section{Front}

The sepulchers of Fuchs are a progression of openings situated on either side of the collarette that permit the stroma and more profound iris tissues to be washed in fluid amusingness. Collagen trabeculae that encompass the fringe of the tombs can be found in blue irises.

$>\quad$ The halfway between the collarette and the root of the iris. These folds result from changes in the surface of the iris as it expands.

Crypts on the base of the iris are extra openings that can be watched near the furthest piece of the ciliary part of the iris.

\section{Back}

$>\quad$ The spiral withdrawal folds of Schwalbe are a progression of fine outspread overlap in the pupillary segment of the iris stretching out from the pupillary edge to the collarette. They are related with the scalloped appearance of the pupillary ruff.

The auxiliary folds of Schwalbe are spiral folds reaching out from the outskirt of the ciliary and pupillary zones that are considerably more extensive and all the more broadly separated, constant with the "valleys" between the ciliary procedures.

Some of the round compression folds are a fine arrangement of edges that keep running close to the pupillary edge and fluctuate in thickness of the iris shade epithelium; others are in ciliary bit of iris.

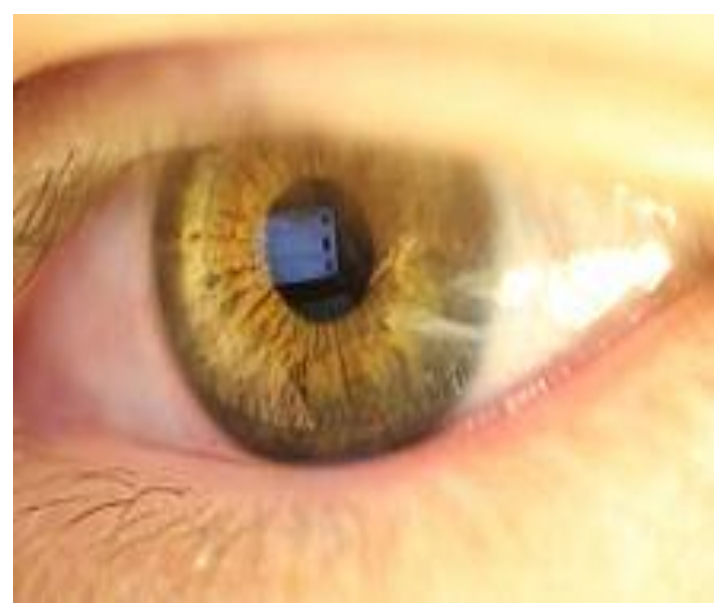

Fig. 2 Example of a green-brown iris

The iris dilator muscle (student dilator muscle, papillary dilator, outspread muscle of iris, emanating filaments), is a smooth muscle of the eye, running radically in the iris and along these lines fit as a dilator. The papillary dilator comprises of a spoke like course of action of altered contractile cells called my epithelial cells. These cells are animated by the thoughtful sensory system. Whenever empowered, the cells contract, augmenting the understudy and taking into consideration all the more light to go through the eye.

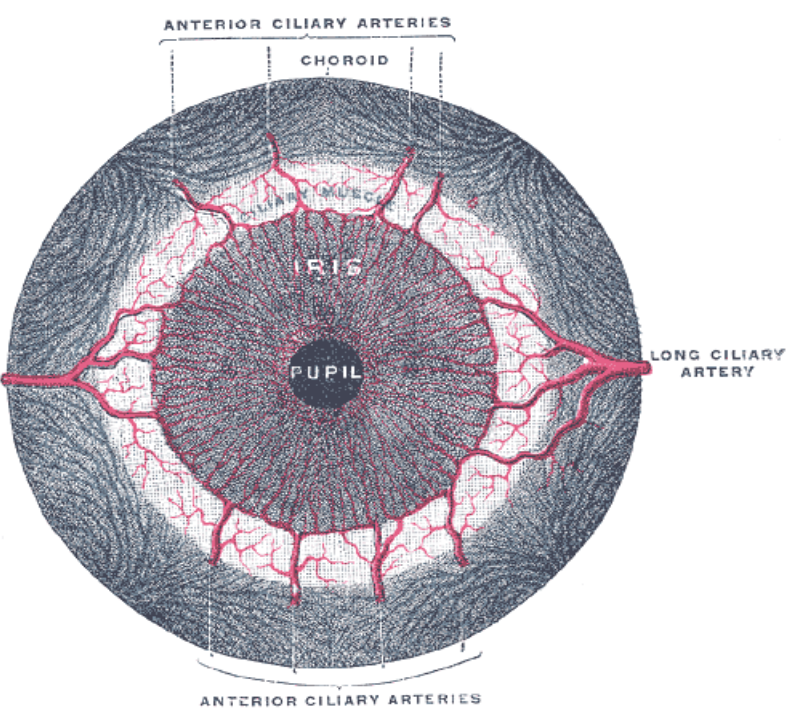

Fig. 3 Iris dilator

The pupillary dilator acts to build the extent of the student to enable all the more light to enter the eye. It works contrary to the pupillary constrictor. Understudy expansion happens when there is deficient light for the typical capacity of the eye, and amid elevated thoughtful movement, for instance in the "battle or flight reflex."

\section{Palm Print}

Palm print acknowledgment has risen as a very acknowledged biometric framework because of its simple securing and unwavering quality. Tribute is the internal exterior of furnish among wrist and fingers.

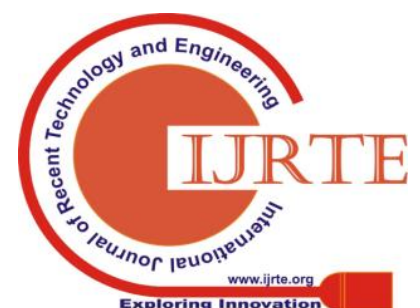


The inward facade of palm contains 3 flexion wrinkles, auxiliary wrinkles, in addition to edges for each finger. The flexion is similarly called as primary lines and optional wrinkles are called wrinkles. Palm highlight additionally incorporates solitary focuses, edges, wrinkle, and delta, datum furthermore details focuses. Palm highlights be novel for each person and has rich data that can be utilized for include extraction [4]. The palm appearance and wrinkles are framed amid third and 5 month of the development of embryo. The wrinkles, edges, central appearance specifically heart lines, features; existence lines are appeared in the fig.4. A environment of intrigue (ROI) is separated from the palm territory for preparing. Palm acknowledgment progression incorporates include pulling out (put away seeing that layout in the database) coordinating (participation question highlights are coordinated through put away highlights) also basic leadership (headed for acknowledge otherwise dismiss the inquiry in light of match score). In this part a diagram of palm print acknowledgment framework, preparing stages and methodologies is displayed.
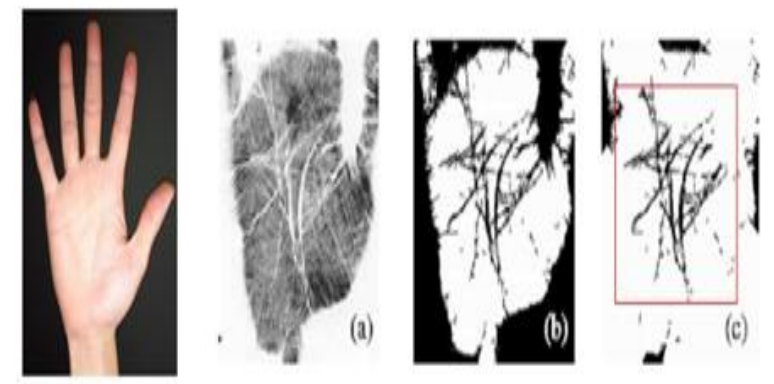

Fig. 4 Feature extraction palm print preconisation

Praise create recognition is a taxonomy confirmation strategy in sight of the one of a kind instances of different merits in the palms of individuals' hands. Palm print tribute frameworks utilize a checking gadget or a camera-based request, alongside related programming that procedures picture information from a photo of a folks palm and thinks about it to a put away record for that person [5]. Palm prints are partners to finger Prints, including comparable subtle elements. Similar to the case with unique finger impression examining, palm scanners utilize optical, tepid or material techniques to copy out the points of interest in the example of raised regions (called edges) and branches (called bifurcations) in a picture of a soul palm, alongside diverse subtle elements including scars, wrinkles and surface. People's three strategies depend on noticeable light investigation, warm outflow test, and mass investigation, alone. Palm scanners may necessitate that people contact their pass to a screen or might be associating Keepsake prints in addition to finger prints are frequently utilized mutually to improve the exactitude of distinguishing proof. An impression, by goodness of jacket supplementary coat zone, incorporate additionally recollect subtle elements, production forged positives the whole thing apart from inconceivable furthermore at the equivalent time production purposeful adulteration drastically more dilemma some. In dissimilar circumstances, for example, criminal examinations, a full or incomplete palm print may at times be gotten when fingerprints are missing. A criminal may, for instance, wear gloves to abstain from leaving finger prints yet incidentally leave an imperfect palm print when a glove slips amid the assignment of a wrongdoing.. Palm vein acknowledgment, a later innovation, utilizes close infrared brightening to uncover the remarkable vascular examples in the palm of a person's hand.

\section{EXISTED METHODS}

Multi biometric frameworks have been presented with the point of decreasing the FAR or potentially FRR and to maintain a strategic distance from parody assaults. These frameworks think about contributions from single or different sensors. Multi algorithmic biometric frameworks utilize at least two calculations for handling a solitary example of a solitary sensor. Multi-occurrence biometric frameworks process utilize at least two distinct examples of the same biometric qualities like different palm prints of a similar individual. Multi sensorial biometric frameworks utilize at least two particularly unique sensors to process a similar trademark. Multimodal biometrics process at least two biometric attributes of a similar person. Diverse blends of the biometric qualities of a similar individual can be utilized. Biometric combination is the way toward consolidating the grouping consequences of each biometric channel. Combination can happen at various levels to be specific coordinating score level, sensor level, include level, rank level and choice level. In sensor level combination biometric attributes taken from various sensors are joined to frame a solitary composite quality. In highlight level combination, include vectors of various biometrics are joined to frame a solitary component vector[6][10]. In coordinating score level combination, individual coordinating scores are found and a choice is made of the score to be utilized for characterization or check. In choice level combination singular biometrics are utilized to settle on singular choices and after that a consolidated choice is touched base at.

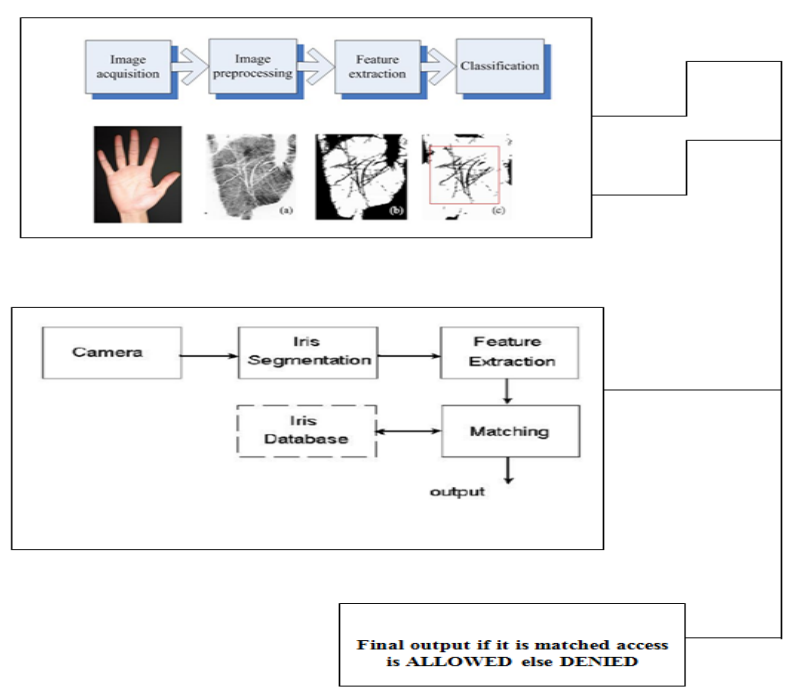

Fig. 5 Existed Method

\section{Published By:}

Blue Eyes Intelligence Engineering

\& Sciences Publication 


\section{PROPOSED METHOD}

In this setting we proposed a progressed multi modular bio metric framework i.e. blend of palm and iris design union. More over this amalgamation is added to profound learning and neural systems. So future extraction is proficient and terrible. Fig.6. demonstrates that existed strategy square chart.

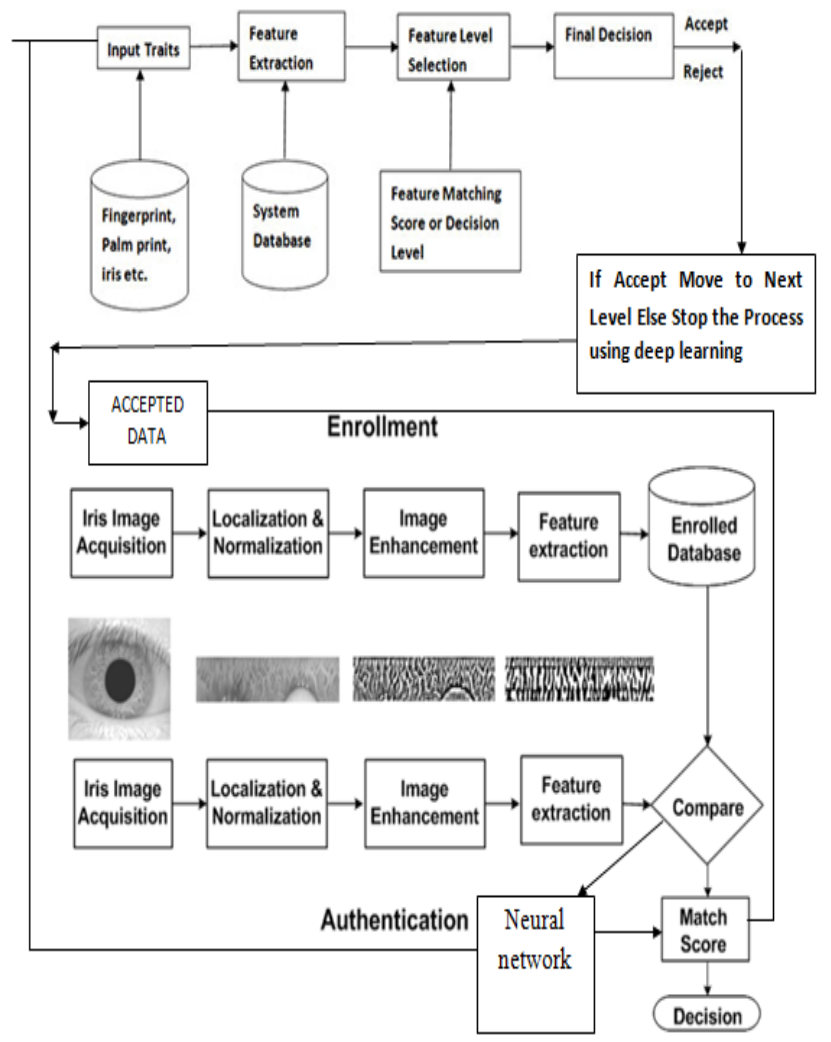

Fig. 6 Proposed block diagram

\section{FUSION BIO-MAXIMUM INVERSE RANK (BMIR) ALGORITHM}

\section{Step: 1}

As a rising biometric innovation, palm print acknowledgment innovation has been explored broadly and grown quickly, which is notable for its high confirmation exactness, low-value catch gadget, high dependability and client acknowledgment. Highlight extraction as a center piece of palm print acknowledgment, can successfully extricate the qualities or not, to a great extent decides the framework acknowledgment rate. Assessing momentum highlight extraction explore, we generally bunch the palm print include extraction calculations into four classifications: structure-based, measurements based, sub space-based and surface and change area highlight based strategies. The motivation behind this broadsheet is to give a refreshed overview of palm print highlight extraction[7]. Subsequent to examining the best in class techniques, the execution of different strategies was looked at and the future propensity was likewise talked about.

\section{Step: 2}

This progression depicts the product usage of Iris Recognition System utilizing Neural Network. This framework means to apply for high security required areas[8]. The interest on security is expanding enormously in these years and biometric acknowledgment step by step turns into a hot field of research. Iris acknowledgment is another part of biometric acknowledgment, which is viewed as the most steady, sheltered and exact biometric acknowledgment strategy. In this strategy, the iris picture information base is made by contributing the advanced photographs by means of Matlab program. Edge recognition, Image limitation, highlight gathering and Neural Networks are fundamentally connected. At long last the precision of iris acknowledgment framework is tried and assessed with various iris images[9].

Usage procedure of this framework can be isolated into 6 sections.

1. Picture obtaining

2. Pre-preparing

3. Confinement Gabor-edge channel

4. Highlight extraction

5. Neural system 6. Result

\section{Step: 3}

At long last utilizing profound learning process strategy for statics give full security to any association or any getting to region.

Step: 4 stop the algorithm.

\section{RESULTS}

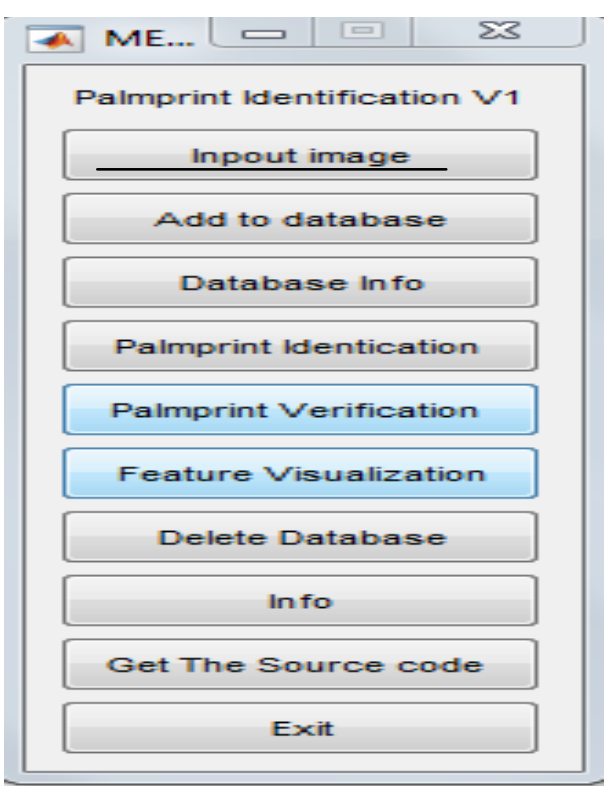

Fig. 7 Palm verification window

Fig.7. clarifies that verification slide bar. Input picture is RGB. It has been changed over into dim scale. Palm print division in advance... if you don't mind pause. Done. Highlight encoding... it would be ideal if you pause. Done. Info picture has been chosen. Presently proceed "Add chosen picture to database" catch to add this picture to database or, go ahead "Palm print Recognition" catch to begin palm print coordinating. 


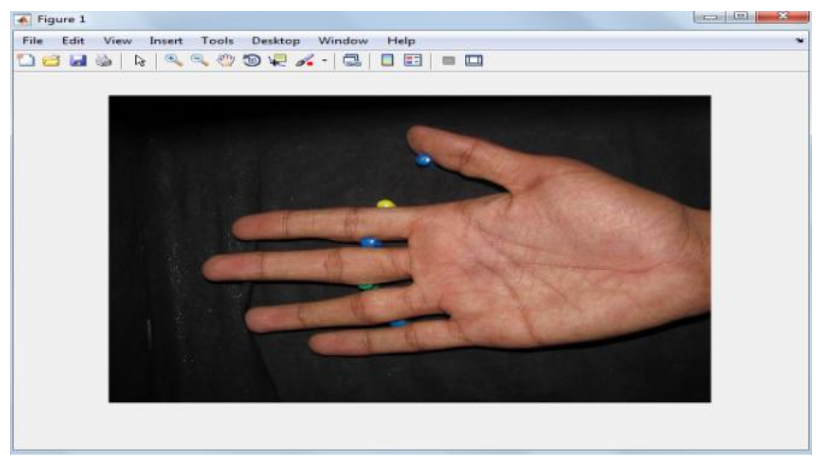

Fig. 8 Input selected palm

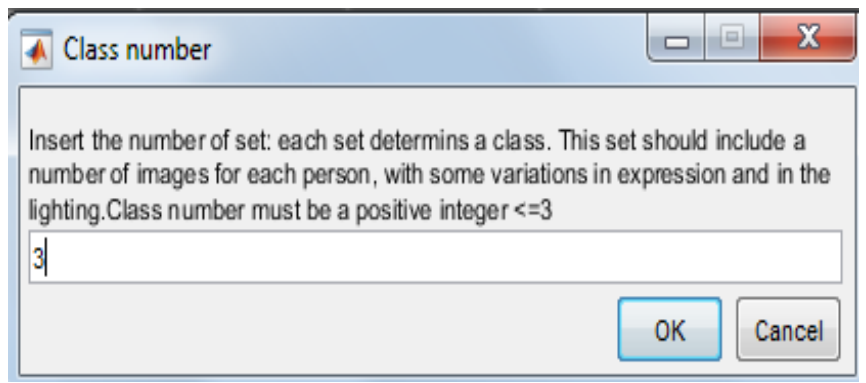

Fig. 9 No. of palm prints added to each person

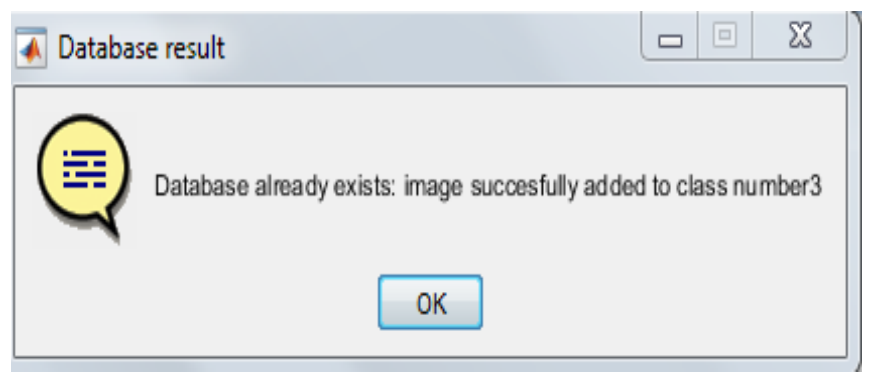

Fig. 10 Data base message and Wavelet \& curvelet transform

Fig.7,8,9, 10 Information picture has been chosen. Presently go ahead "Add chosen picture to database" catch to add this picture to database or, go ahead "Palmprint Recognition" catch to begin palm print coordinating.

\section{Selected image1}

D: IpHd clientslklu ahamad imagelbio metrics\New folder\PalmPrint $D$ ataBaselIMG_001 (2).JPG Input picture is RGB. It has been changed over into grayscale. Palmprint division in advance... if you don't mind pauses.

Status: NOT RECOGNIZED

Distance: 0.48971

\section{Selected image2}

D:IpHd clientslklu ahamad imagelbio metrics\New folder|Palm PrintlData BaselIMG_005 (6).JPG Input picture is RGB. It has been changed over into greyscale. Palm print division in advance... please wait.

Status: RECOGNIZED

Distance: 0

\section{Feature Extraction}

Palm_print segmentation in progress... please wait. Done. Feature encoding... please wait. Done.

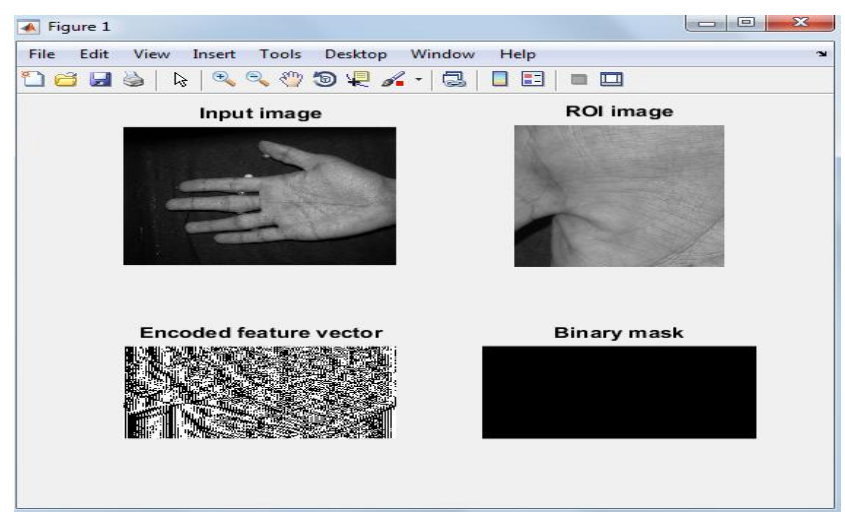

Fig. 11 Neural networks based feature extraction

Fig.11. shows that neural and binary extracted methods. So we got better accuracy

\section{In Step 2: Iris Based Authentication}

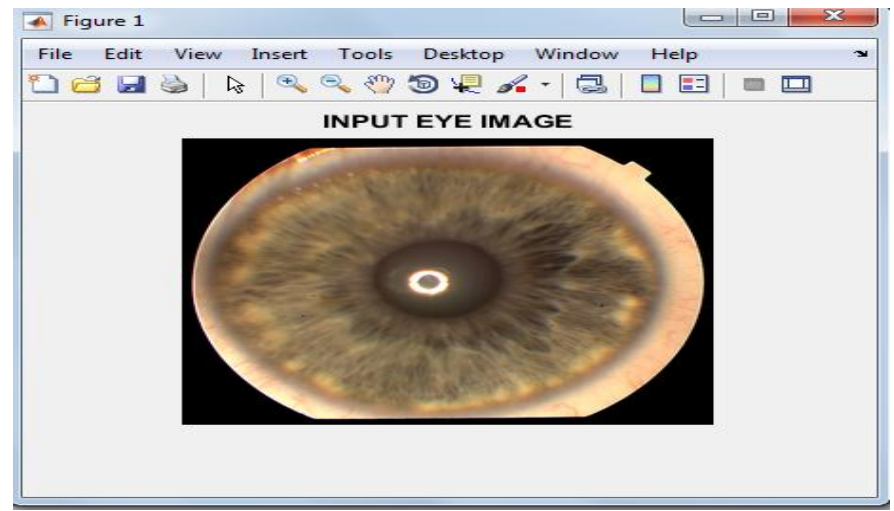

Fig. 12 Input iris image

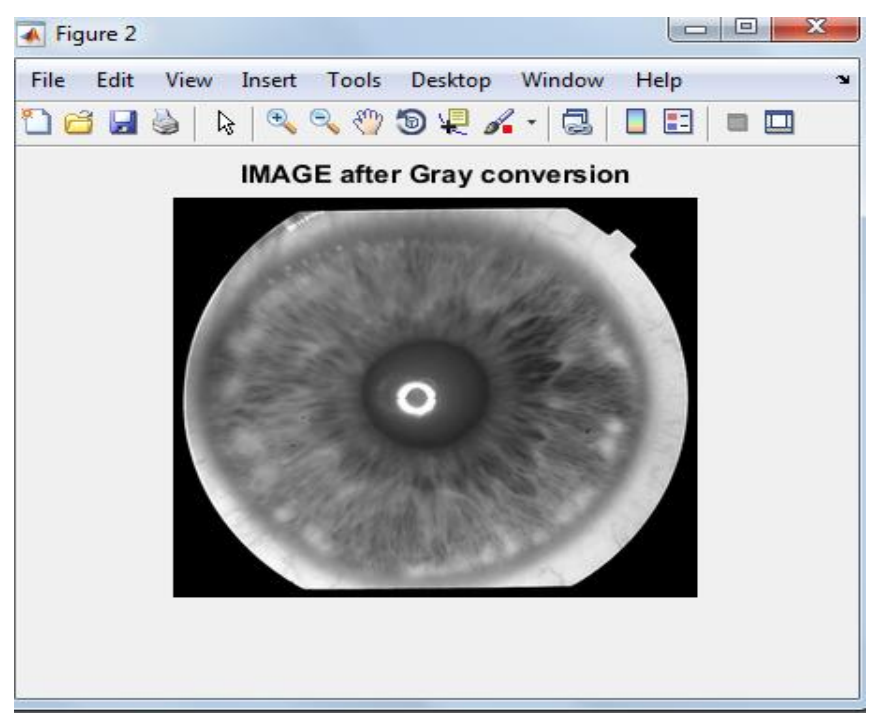

Fig. 13 Gray scale image

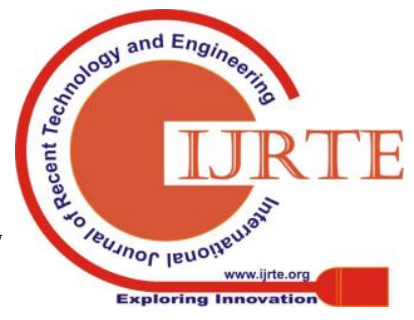


A Multi Biometric IRIS Recognition System Based on a Profound Learning Method

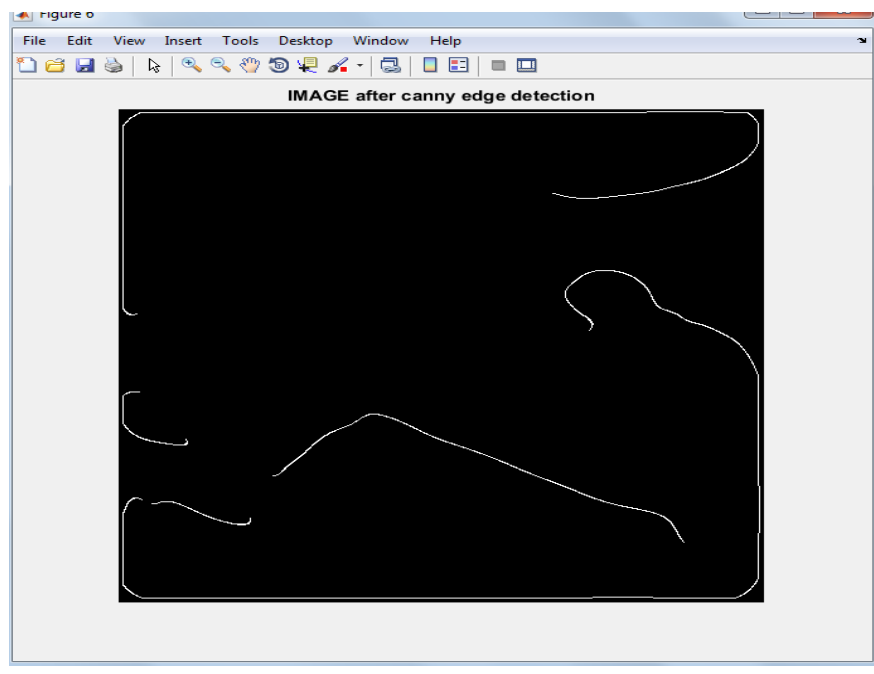

Fig. 14 Neural network IRIS

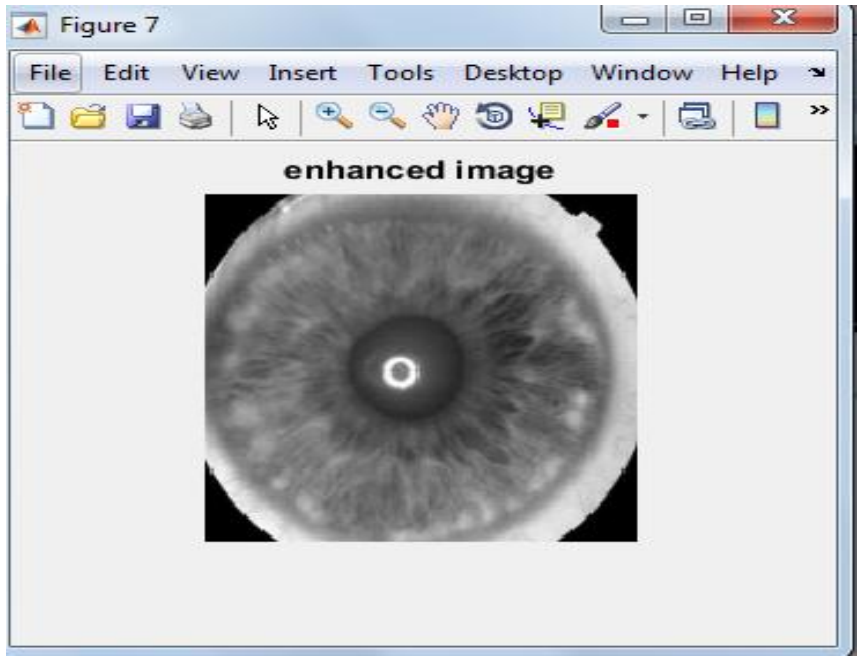

Fig. 15 Enhanced iris using deep learning

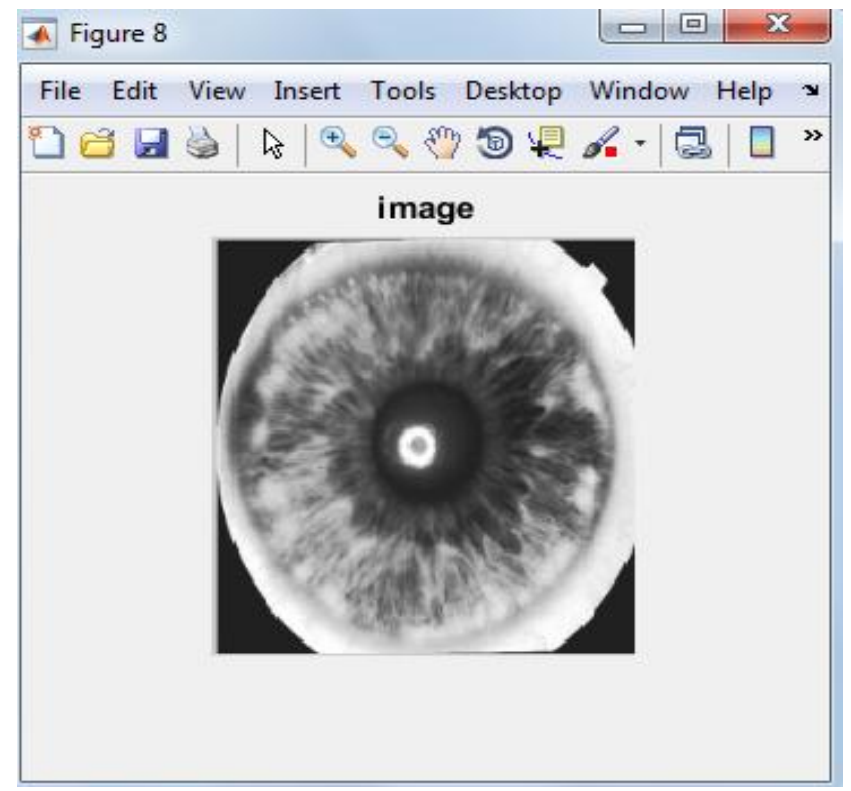

Fig. 16 Final trained IRIS

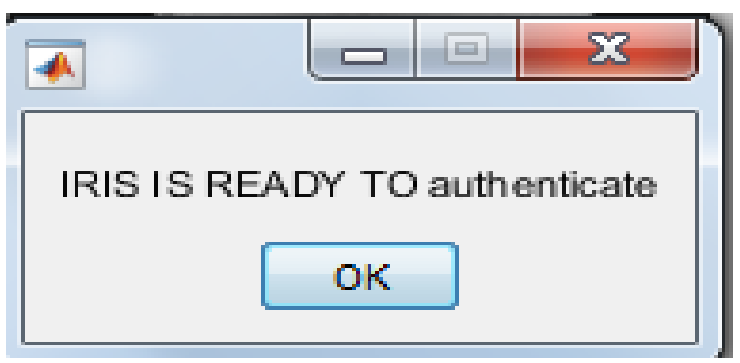

Finally IRIS is trained.
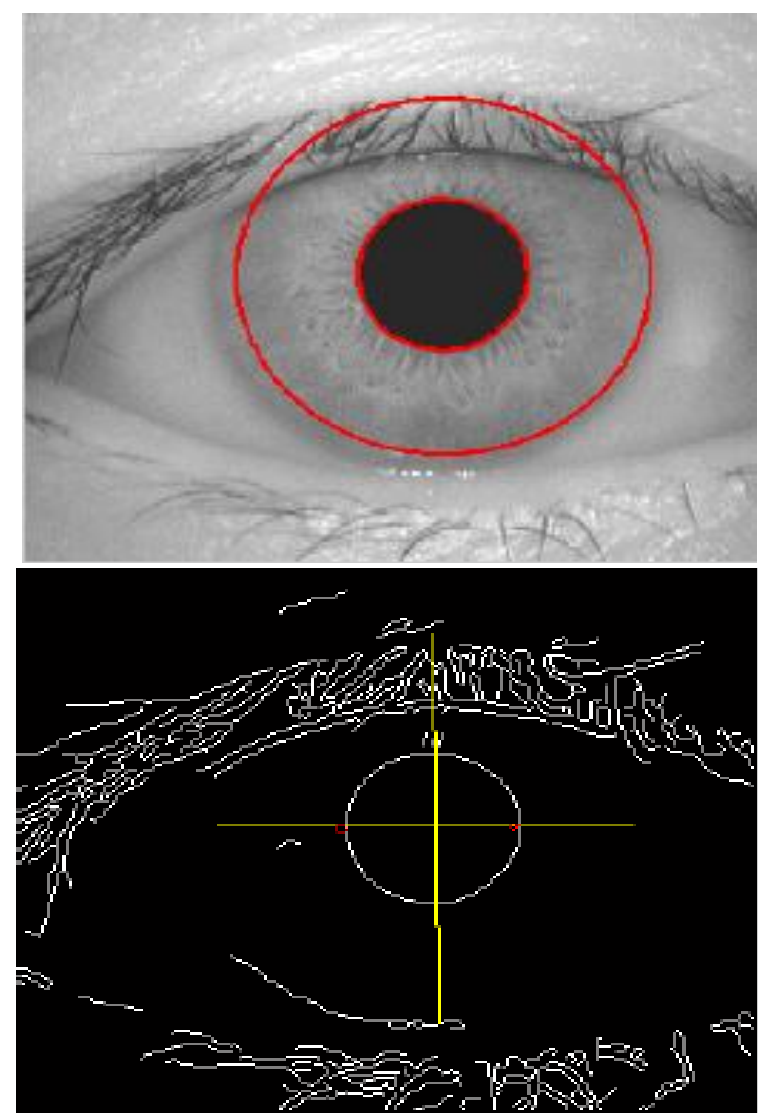

Fig. 17 Distance finding Status: NOT RECOGNIZED Distance: 0.48971

Figure: 12, 13, 14,15,16,17 explains that bio metrics trained images of our works and below table 1 and 2 explains that software and deep learning process data

Table. 1 Deep Learning Data

\begin{tabular}{|l|l|l|l|l|}
\hline $\begin{array}{l}\text { Iris Data } \\
\text { Base }\end{array}$ & $\begin{array}{l}\text { No of } \\
\text { Train } \\
\text { files }\end{array}$ & $\begin{array}{l}\text { No of } \\
\text { Test files }\end{array}$ & $\begin{array}{l}\text { correct } \\
\text { for Train } \\
\text { files }\end{array}$ & $\begin{array}{l}\text { correct } \\
\text { for Test } \\
\text { file }\end{array}$ \\
\hline $\begin{array}{l}\text { Data } \\
\text { Base } 001\end{array}$ & 3 & 2 & 3 & 2 \\
\hline $\begin{array}{l}\text { Data } \\
\text { Base } 002\end{array}$ & 3 & 2 & 3 & 2 \\
\hline $\begin{array}{l}\text { Data } \\
\text { Base } 003\end{array}$ & 3 & 2 & 3 & 1 \\
\hline
\end{tabular}

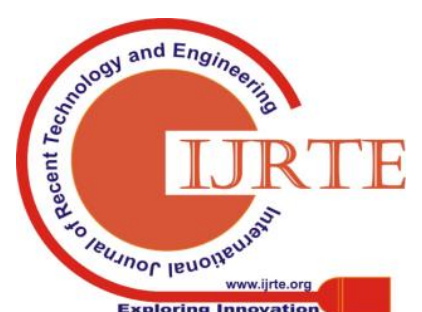


Table. 2 Software Requirements

\begin{tabular}{|l|l|}
\hline \multicolumn{1}{|c|}{ TYPE } & $\begin{array}{l}\text { VERSION OR GENERAL } \\
\text { PROPERTIES }\end{array}$ \\
\hline Software & $\begin{array}{l}\text { Matlab R2008b, Image } \\
\text { Processing Tool box GUI }\end{array}$ \\
\hline
\end{tabular}

\section{CONCLUSION}

In this paper we have utilized iris, palm print and iris based acknowledgment as building squares to make a multimodular acknowledgment framework. A few surely understood combination calculations have been utilized keeping in mind the end goal to join the yield of individual modules.

We have additionally proposed another converse rankbased combination strategy (IRF). This work gives better outcomes contrasted with past work.

\section{REFERENCES}

1. A multi-biometric iris recognition system based on a deep learning approach https://doi.org/10.1007/s10044-017-0656-1

2. D. S. Thepade and P. R. Mandal, "Novel iris recognition technique using fractional energies of transformed iris images using haar and kekre transforms," International Journal Of Scientific \& Engineering Research, vol. 5, no. 4, 2014

3. J. Daugman, "How iris recognition works," Circuits and Systems for Video Technology, IEEE Transactions on, vol. 14, no. 1, pp. 21-30, 2004.

4. S. Sheela and P. Vijaya, "Iris recognition methods-survey," International Journal of Computer Applications, vol. 3, no. 5, pp. 19$25,2010$.

5. J. Wang and M. Xie, "Iris feature extraction based on wavelet packet analysis," in Communications, Circuits and Systems Proceedings, 2006 International Conference on, vol. 1. IEEE, 2006, pp. 31-34.

6. http://www.ncits.org/tc_home/ m1htm/docs/ m1020044.pdf. Lim, S., Lee, K., Byeon, O., Kim, T, "Efficient Iris Recognition through Improvement of Feature Vector and Classifier", ETRI Journal, Volume 23, Number 2, June 2001

7. Jain, A., Duin, R. and Mao, J. 2000. "Statistical Pattern Recognition: A Review" IEEE Transactions on Pattern Analysis and Machine Intelligence, vol. 22, pp. 436-437. Pavlidis, T. 1977. Structural Pattern Recognition. Springer-Verlag, New York.

8. Wildes, R.P, "Iris Recogntion: An Emerging Biometric Technology", Proceedings of the IEEE, VOL. 85, NO. 9, September 1997. Howard Demuth, Mark Beale, Martin Hagan 1998. Neural Network Toolbox ${ }^{\mathrm{TM}}$ 6, User's guide, the Math Works Inc.

9. Mo Myint Wai, "Software Implementation of Iris Recognitio System using Wavelet Transformation," proceeding of ICSE09, International Conference on Science and Engineering, Yangon, Myanmar, 2009.

10. Abhiram MH, Sadhu C, Manikantan K, Ramachandran S (2012) Novel DCT based feature extraction for enhanced iris recognition. In: Proceedings-2012 international conference on communication, information and computing technology ICCICT 2012. pp 1-6. 